\title{
Medical students' perception of nutrition education at an undergraduate level - an experience of two medical school courses
}

\author{
F. Tripisciano ${ }^{1}$, A. Hills ${ }^{1}$ and P. Neild ${ }^{2}$ \\ ${ }^{1}$ Barts and the London School of Medicine and Dentistry, Centre for Medical Education, Old Medical College Building, \\ Turner Street, Whitechapel, London E1 2AD, UK and ${ }^{2}$ St George's University of London, Cranmer Terrace, \\ London SW17 ORE, UK
}

\begin{abstract}
Medical schools have often been found to neglect the teaching of clinical nutrition in their undergraduate courses ${ }^{(1)}$. It is increasingly acknowledged that nutrition plays an important role in health and disease, yet many doctors do not feel confident enough to offer nutritional advice to their patients ${ }^{(2)}$. The aim of this study was to explore medical students' views and experiences of undergraduate nutrition education at different stages of their training and on different style courses.

A cross-sectional email survey of all medical students in the first and final years of the MBBS4 and MBBS5 courses at St George's, University of London was conducted. The overall response rate was 188/549 (34.2\%), with no significant differences between the two courses or year groups. Frequency distributions and chi-squared tests were used to compare student opinion in the different year groups and courses.

Ninety-four percent of all the students believed that having a good understanding of nutrition is an important part of a doctor's job and $86 \%$ thought that nutrition education should be included in the undergraduate medical curriculum. However, a significantly higher proportion of students in their final year of medical school (compared to those in their first year) were less certain about the importance of nutrition in a doctor's job $(12.8 \%$ versus $1.0 \%, P<0.001)$ and whether teaching on nutrition should be included in the medical curriculum $(19.8 \%$ versus $8.8 \%, P=0.030)$. Over $81 \%$ of all the final year medical students had only 'occasionally' or 'rarely' had the importance of nutrition highlighted to them by senior clinicians.

Approximately three-quarters of the students indicated that they would prefer nutrition teaching to be integrated with other modules in the medical course rather than given in a separate block. Seventy two percent of final year students felt that they had not received enough nutrition teaching in their course and over $90 \%$ considered their overall knowledge of nutrition to be only either 'satisfactory' or 'poor'. However, a significantly higher proportion of students in their final year of the MBBS4 course considered their knowledge of nutrition to be 'good' compared to those on the MBBS5 course ( $16.7 \%$ versus $2.9 \%, P=0.027)$.

Generally there was otherwise very little difference in the views of the students, regardless of their year or style of course. The outcomes of this study highlight that there is still a need for nutrition education to be improved in medical schools and suggest that senior role models may be important in developing and maintaining interest and enthusiasm for this subject.
\end{abstract}

1. Brett A, Godden DJ \& Keenan R (1986) Hum Nutr-Appl Nutr 40, 217-222.

2. Buttriss JL (1997) Am J Clin Nutr 65, 1985S-1995S. 